\title{
Bioanalysis
}

\section{LC-MS/MS-based quantification of kynurenine metabolites, tryptophan, monoamines and neopterin in plasma, cerebrospinal fluid and brain}

\begin{abstract}
Aim: The kynurenine (KYN) pathway is implicated in diseases such as cancer, psychiatric, neurodegenerative and autoimmune disorders. Measurement of KYN metabolite levels will help elucidating the involvement of the KYN pathway in the disease pathology and inform drug development. Methodology: Samples of plasma, cerebrospinal fluid or brain tissue were spiked with deuterated internal standards, processed and analyzed by LC-MS/MS; analytes were chromatographically separated by gradient elution on a $\mathrm{C} 18$ reversed phase analytical column without derivatization. Conclusion: We established an LC-MS/MS method to measure 11 molecules, namely tryptophan, KYN, 3-OH-KYN, 3-OH-anthranilic acid, quinolinic acid, picolinic acid, kynurenic acid, xanthurenic acid, serotonin, dopamine and neopterin within $5.5 \mathrm{~min}$, with sufficient sensitivity to quantify these molecules in small sample volumes of plasma, cerebrospinal fluid and brain tissue.
\end{abstract}

First draft submitted: 2 May 2016; Accepted for publication: 26 July 2016;

Published online: 24 August 2016

Keywords: biomarker $\bullet$ IDO $\bullet$ indoleamine-2,3-dioxygenase $\bullet$ kynurenic acid $\bullet$ kynurenine - LC • neopterin $\bullet$ neurotransmitters $\bullet$ quinolinic acid $\bullet$ MS/MS

The kynurenine (KYN) pathway is the major degradation pathway of tryptophan (TRP) in the body. Three enzymes are known to catalyze the breakdown of TRP into KYN, namely TRP-2,3-dioxygenase (TDO), indoleamine-2,3-dioxygenase-1 (IDO-1) and recently discovered IDO-2 $[1,2]$. These three enzymes differ in their localization, type of induction and substrate specificity. The majority of total TRP is degraded by TDO in the liver; degradation products of this liver metabolism are NAD as well as adenosine triphosphate [3]. IDO-1 and IDO-2 are expressed in various cell types, are inducible by a number of cytokines and other bioactive molecules and are involved in autoimmunity, T-cell regulation, maternal-fetal immune tolerance and more [4-7]. The KYN pathway has been implicated in the pathophysiology of several diseases, for example, neurodegenerative disorders as well as cancer and infec- tious diseases for a considerable time. More recently, interest in this pathway re-emerged in the context of several diseases including cancer, infection, autoimmune disorders and psychiatric disorders (for reviews, refer to $[4,8-10])$.

$\mathrm{KYN}$ is the precursor of various metabolites with quite diverse biological functions. KYN itself is a ligand at the aryl-hydrocarbon receptor and thereby regulates gene expression and immune function $[11,12]$. It can be metabolized along three different branches of the pathway, depending on the enzyme repertoire of the relevant cells (Figure 1) [13]. Along the KYN-3-monoxygenase (KMO) branch, $\mathrm{KYN}$ is converted to 3-hydroxykynurenine (3-HK) which itself is further degraded to 3-hydroxyanthranilic acid (3-HAA). Both metabolites are able to produce free radicals and may cause tissue damage when generated in excess [14,15]. Another redox active
René Fuertig*,1, Angelo Ceci', Sandrine M Camus ${ }^{2}$, Erwan Bezard ${ }^{2,3,4}$, Andreas H Luippold 5 \& Bastian Hengerer ${ }^{1}$

${ }^{1}$ CNS Diseases Research, Boehringer Ingelheim Pharma GmbH \& Co. KG, Birkendorfer Strasse 65, 88397 Biberach an der Riss, Germany

${ }^{2}$ Motac Neuroscience, Manchester, UK

${ }^{3}$ Univ de Bordeaux, Institut des Maladies Neurodégénératives, UMR 5293,

F-33000 Bordeaux, France

${ }^{4}$ CNRS, Institut des Maladies Neurodégénératives, UMR 5293, F-33000 Bordeaux, France

${ }^{5}$ Drug Discovery Support, Boehringer Ingelheim Pharma GmbH \& Co. KG, Birkendorfer Strasse 65, 88397 Biberach an der Riss, Germany

*Author for correspondence: rene.fuertig@boehringer-ingelheim.com 


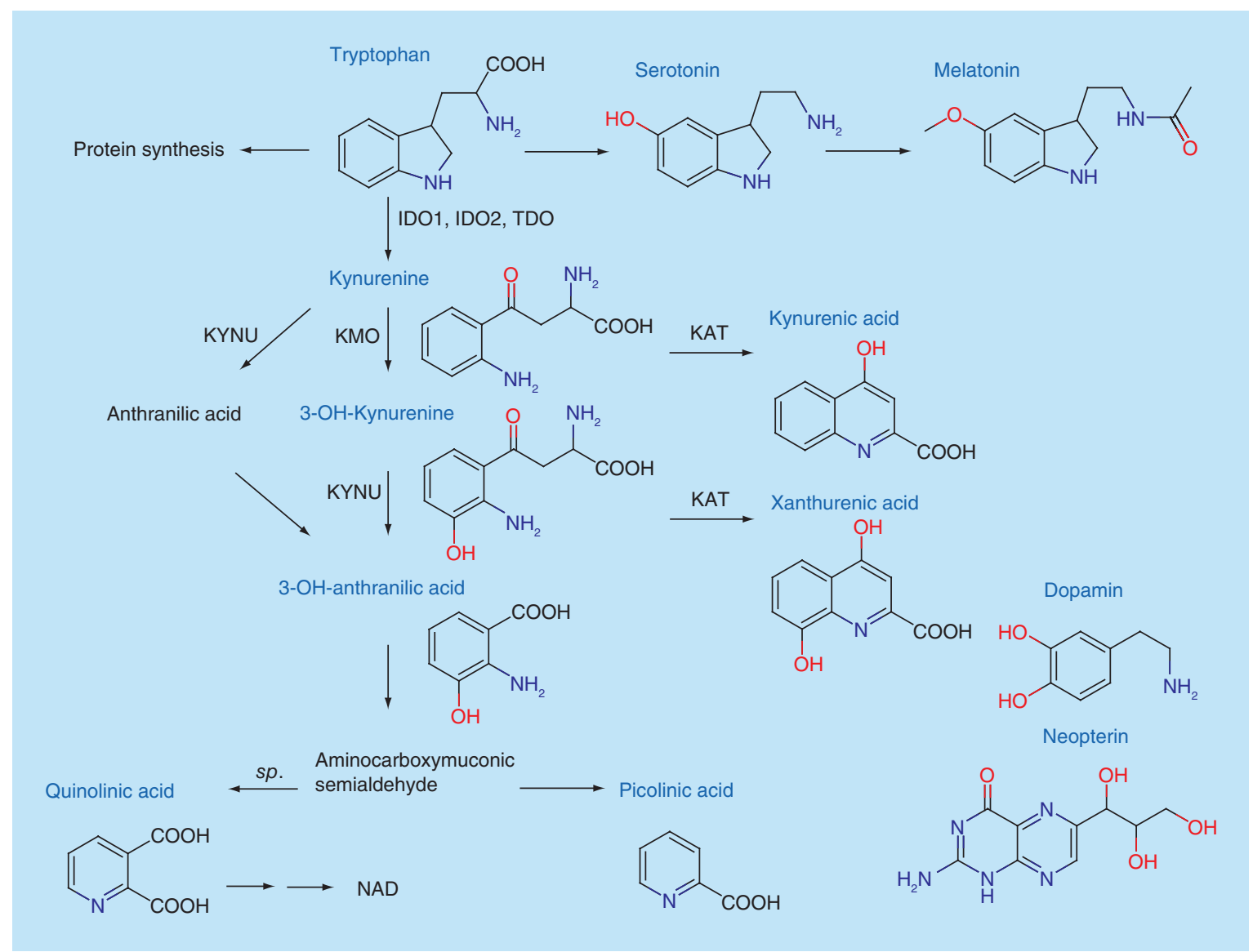

Figure 1. Tryptophan metabolic pathways and related molecules. Chemical structure is given for molecules for which the method has been developed and their names are highlighted in blue.

sp.: Spontaneous reaction.

intermediate in the second branch - the kynureninase (KYNU) branch - is anthranilic acid [16]. Unspecific hydroxylation of anthranilic acid may also lead to 3-HAA [17]. That means there are two independent pathways of 3-HAA production. However, it seems that in mammals, or at least in rats, the pathway via 3-HK is the preferred route of 3-HAA biosynthesis [18]. 3-HAA is further metabolized into aminocarboxymuconic semialdehyde, an unstable intermediate which is nonenzymatically transformed into quinolinic acid (QUIN), and is also the precursor of picolinic acid (PICO). QUIN is an agonist at the glutamatergic $\mathrm{N}$-methyl-D-aspartate receptor and can cause excitotoxicity, whereas PICO is thought to be neuroprotective $[19,20]$. QUIN is also the precursor of niacin and, therefore, NAD production. The third branch of the KYN pathway is initiated by KYN aminotransferases (KAT) I-IV which metabolize KYN to kynurenic acid (KYNA), an antagonist at $N$-methyl-D-aspartate and $\alpha 7 \mathrm{nACh}$ receptors and agonist at GPR35 [21-26]. However, in the brain KAT II seems to be the major isoform contributing to KYNA production [25,26]. 3-HK is also a substrate for KATs and leads to the production of xanthurenic acid (XANA), another metabolite involved in neurotransmission as it is an agonist at group II metabotropic glutamate receptors [27,28]. Furthermore, TRP as the precursor of KYN, is also the precursor of the neurotransmitter serotonin (5-HT) and melatonin (MEL), two molecules of utmost importance for brain functioning and circadian rhythm. Dopamine (DA) as another neurotransmitter is also very important in neuronal signaling and seems to interplay with KYNA [29]. Neopterin (NEO) is a biomarker for inflammatory conditions and is upregulated by IFN $-\gamma$, as is IDO-1. Therefore, it could serve as a biomarker for activation of the KYN pathway or inflammatory conditions in studied subjects [6,30-32].

This quite broad spectrum of biological activities underlines the importance of targeted assessment of changes in KYN pathway metabolites (or more general: TRP catabolites [TRYCATs] which would include TRP and its catabolites including 5-HT and MEL) and related neurotransmitters like 5-HT and DA as well as NEO for research purposes in several indication areas. Prerequisites are the simultaneous detection of TRYCATs and related analytes with sufficient sensi- 
tivity and specificity. Furthermore, an acceptable analytical run-time is necessary to allow sufficient sample throughput and thereby fulfilling research needs. For standardization and reproducibility of measurements, sample preparation procedures should be standardized and as easy as possible.

Challenges in the development of a single method to analyze TRYCATs, neurotransmitters and NEO are: the different polarity and functional groups leading to differential chromatographic behavior and ionization effects (also see chemical structures in Figure 1) and the marked differences in endogenous levels. Endogenous plasma TRP levels, for example, are in the mid micromolar range $(\sim 40-90 \mu \mathrm{M})$ whereas baseline concentrations of NEO in plasma are usually in the low nanomolar range $(\sim 1-25 \mathrm{nM})[33,34]$. This means that there is a need of lower sensitivity for some analytes while maintaining high sensitivity for others, whereas sample dilution as well as sample concentrating procedures are limited.

In the past, a variety of analytical methods have been developed to measure TRYCATs including liquid chromatographic methods with UV and fluorescence detection as well as GC and LC coupled to MS [33,35-43]. However, to the best of our knowledge, no method has been reported, which is able to analyze the whole spectrum of TRYCATs and related molecules like 5-HT, MEL, DA and NEO with adequate sensitivity to allow for determination not only in plasma but also in brain tissue and cerebrospinal fluid (CSF), which is easy to use, qualified fit-for-purpose and with optimized throughput. Furthermore, research compounds which are usually much more lipophilic than the described biomarkers, such as an IDO1 inhibitor, can be and are introduced in the method. Hence, we describe the development of an LC-MS/MS method which covers TRP and seven of its KYN metabolites (KYN, 3-HK, 3-HAA, KYNA, XANA, QUIN and PICO) and related molecules (5-HT, DA, NEO), in combination with the potential possibility to measure pharmaceutical compounds in the same run. This method has adequate sensitivity to assess biomarker levels in various biological matrices including brain tissue and CSF in small sample volumes with a sufficient throughput for pharmaceutical research. Method qualification to display fit-for-purpose use has been performed in relation to the EMA and US FDA guidelines on bioanalytical method validation $[44,45]$. Accuracy and precision are verified by the use of stable deuterium-labeled internal standards (IS) (d5-TRP, d4-KYN, d5-KYNA, d3-QUIN, d4-5-HT, d4-DA). Herein, we provide three examples for the application of this method: nonhuman primates were treated with L-KYN and the metabolism of plasma TRYCATs was investigated over time compared with vehicle treatment, and CSF levels $2 \mathrm{~h}$ after administration were assessed. Endogenous baseline levels of all analytes were assessed in mouse plasma, and in brain tissue punches from ten mouse brain regions (infralimbic cortex [IL]; anterior cingulate cortex $[\mathrm{ACC}]$; caudate putamen $[\mathrm{CPu}]$; nucleus accumbens [NAcc]; BLA-Amygdala; dorsal hippocampus [dHIP]; ventral hippocampus [vHIP]; ventral tegmental area [VTA]; dorsal raphe nucleus [DRN]; median raphe nucleus [MRN]).

\section{Materials \& methods}

\section{Chemicals \& reagents}

TRP, KYN, 3-OH-KYN, 3-OH-anthranilic acid, QUIN, PICO, KYNA, XANA, 5-HT, DA, NEO and MEL as well as formic acid (FA), trifluoroacetic acid (TFA) and methanol (MeOH; FLUKA, LC-MS grade) were obtained from Sigma Aldrich (Steinheim, Germany). Acetonitrile (ACN) in LC-MS grade and dimethyl sulfoxide were purchased from Roth Chemicals (Carl Roth GmbH \& Co. KG, Karlsruhe, Germany). The following stable isotope-labeled IS were used: d4-KYN and d3-quinolinic acid (Buchem BV, Apeldoorn, The Netherlands), d5-kynurenic acid (CDN Isotopes, QC, Canada), d5-tryptophan (Sigma Aldrich, Steinheim, Germany), d4-serotonin (as creatinine sulfate complex) and d4-dopamine (as hydrochloride) (Cambridge Isotope Laboratories, Inc., MA, USA). IDOInh was synthesized in-house.

All standards, solvents and reagents used were of highest purity (LC-MS grade where available).

AcroPrep ${ }^{\mathrm{TM}}$ Advance 96 Filter Plate 3K Omega filtration plates with a molecular weight cutoff of $3 \mathrm{kDa}$ were purchased from Pall (Pall Corporation, MI, USA).

\section{LC-MS/MS system}

The LC-MS/MS system consisted of a CTC HTC PAL Autosampler (CTC Analytics AG, Zwingen, Switzerland) and an Agilent 1200 Series LC system (Micro Vacuum Degasser, Binary Pump SL, Thermostatted Column Compartment; Agilent Technologies, Waldbronn, Germany), coupled to an API $4000^{\mathrm{TM}}$ triple quadrupole mass spectrometer (AB Sciex, Darmstadt, Germany). Data acquisition and processing were carried out using Analyst ${ }^{\circledR}$ software Version 1.6.2.

\section{Preparation of standard \& IS stock solutions}

Stock solutions were prepared individually for each standard and IS in a final concentration of $1 \mathrm{mmol} / \mathrm{l}$. According to their solubility and stability in solution, several solvents and mixtures were used: TRP, d5-TRP, 3-HAA, PICO, QUIN, d3-QUIN, 5-HT and $\mathrm{d} 4-5-\mathrm{HT}$ were dissolved in water/methanol/FA/ 
ascorbic acid (50/50/0.1/0.02). KYN, d4-KYN, 3-HK and MEL were dissolved in $\mathrm{MeOH}$ with $0.1 \%$ formic and $0.02 \%$ ascorbic acid. DA and d4-DA were dissolved in water with $0.1 \%$ formic and $0.02 \%$ ascorbic acid. KYNA, d5-KYNA, XANA and NEO were dissolved in dimethyl sulfoxide.

All standard stocks were prepared on ice; aliquots were aerated with nitrogen and stored at $-80^{\circ} \mathrm{C}$ until use.

Preparation of working dilutions for calibration \& IS

Stock solutions were diluted with acidified mobile phase $(0.2 \% \mathrm{FA} / 0.05 \% \mathrm{TFA} / 1 \% \mathrm{ACN}$ in water; components similar to mobile phase $\mathrm{A}$, higher concentration of organic acids) to generate standard dilution mixtures of all standards in a range of $0.1-10,000 \mathrm{nmol} / \mathrm{l}$ for analysis of brain tissue and CSF and 1-100,000 nmol/1 for analysis of plasma. Calibration standards were prepared with concentrations of $1 \times 10^{\times}, 2.5 \times 10^{\times}, 5 \times$ $10^{\times}, 7.5 \times 10^{\times} \mathrm{mol} / \mathrm{l}(\mathrm{x}=-10,-9,-8,-7,-6,-5,-4)$. An internal standard mix (IS-MIX) was prepared in acidified mobile phase with the following concentrations: d5-TRP $10 \mu \mathrm{mol} / \mathrm{l}$, d4-KYN $1 \mu \mathrm{mol} / \mathrm{l}, \mathrm{d} 4-5-\mathrm{HT}$ $1 \mu \mathrm{mol} / \mathrm{l}$, d4-DA $1 \mu \mathrm{mol} / \mathrm{l}$, d3-QUIN $1 \mu \mathrm{mol} / \mathrm{l}$, d5-KYNA $0.1 \mu \mathrm{mol} / \mathrm{l}$. These concentrations were chosen based on endogenous levels of analytes and an adequate $\mathrm{S} / \mathrm{N}$ to ensure reliable peaks.

Preparation of calibration standards, samples \& quality control samples

Plasma

To $10 \mu \mathrm{l}$ of plasma sample or $10 \mu \mathrm{l}$ of calibration standard, $10 \mu \mathrm{l}$ of IS-MIX and $10 \mu \mathrm{l}$ of acidified mobile phase were added (quality control samples [QCs] were prepared according to the method of standard addition: QCs consisted of $10 \mu \mathrm{l}$ pooled plasma from study samples $+10 \mu \mathrm{l}$ IS-MIX and $10 \mu \mathrm{l}$ calibration standard without addition of acidified mobile phase). Subsequently $150 \mu \mathrm{l}$ ice-cold $\mathrm{MeOH}$ was added and this mixture was allowed to rest for $30 \mathrm{~min}$ at $-20^{\circ} \mathrm{C}$ to support protein precipitation. After centrifugation $\left(3000 \times g, 4^{\circ} \mathrm{C}, 15 \mathrm{~min}\right)$ supernatants were removed and evaporated to dryness under a gentle stream of nitrogen. Dried extracts were reconstituted in $50 \mu \mathrm{l}$ of acidified mobile phase. Twenty microliters were injected into the LC-MS/MS system. No additional filtration step was necessary. All steps including the evaporation were carried out in 96-well plates to provide sufficient sample throughput.

\section{Cerebrospinal fluid}

To $10 \mu \mathrm{l}$ of CSF or calibration standard, $10 \mu \mathrm{l}$ of ISMIX and $10 \mu \mathrm{l}$ of acidified mobile phase were added
(QCs were prepared according to the method of standard addition: QCs consisted of $10 \mu \mathrm{l}$ pooled CSF from study samples + $10 \mu \mathrm{l}$ IS-MIX and $10 \mu \mathrm{l}$ calibration standards). A total of $150 \mu \mathrm{l}$ ice-cold $\mathrm{MeOH}$ was added and the mixture was allowed to rest for $30 \mathrm{~min}$ at $-20^{\circ} \mathrm{C}$ to support protein precipitation. After centrifugation $\left(3000 \times g, 4^{\circ} \mathrm{C}, 15 \mathrm{~min}\right)$, the supernatant was collected and evaporated to dryness under a gentle stream of nitrogen. The dried extract was reconstituted in $40 \mu \mathrm{l}$ of acidified mobile phase. A total of $20 \mu \mathrm{l}$ were injected into the LC-MS/MS system. No additional filtration step was necessary. All steps, including the evaporation, were carried out in 96-well plates to allow for sufficient sample throughput.

\section{Brain tissue}

Various amounts of tissue can be applied. Usually samples between 1 and $20 \mathrm{mg}$ were processed in the following way: to weighed brain samples, $50 \mu \mathrm{l}$ of acidified mobile phase and $10 \mu \mathrm{l}$ of IS-MIX were added. For calibration standards, $50 \mu \mathrm{l}$ of standard was used instead of acidified mobile phase; calibration standards were prepared without brain tissue. QCs were prepared according to the method of standard addition. For QCs, to $50 \mu \mathrm{l}$ of standard and $10 \mu \mathrm{l}$ of IS-MIX, $10 \mu \mathrm{l}$ of a brain homogenate pool from study samples was added. Those $10 \mu \mathrm{l}$ contained approximately the same amount of tissue as the average amount of tissue per study sample in order to generate similar matrix effects. To each of those mixtures $200 \mu \mathrm{l}$ of ice-cold $\mathrm{MeOH}$ was added and subsequently homogenized using a supersonic homogenizer for $10 \mathrm{~s}$. At this stage, calibration standards, samples and QCs were transferred onto a 96-well plate to provide sufficient throughput. To support protein precipitation, plates were allowed to rest in the freezer for $30 \mathrm{~min}$. After centrifugation $\left(3000 \times g, 4^{\circ} \mathrm{C}, 15 \mathrm{~min}\right)$ supernatants were removed and evaporated to dryness under a gentle stream of nitrogen and dried extracts were reconstituted in an appropriate volume of acidified mobile phase (range of 30 to $300-500 \mu \mathrm{l}$, depending on the amount of tissue used). A total of $20 \mu \mathrm{l}$ were injected into the LC-MS/MS system. No additional filtration step was necessary.

Alternative sample preparation by ultrafiltration to increase throughput

Instead of protein precipitation with methanol, we introduced ultrafiltration (membrane cutoff $3 \mathrm{kDa}$ ) to remove proteins and other molecules from plasma, brain and CSF samples. After loading the 96-well plates with the above mixtures from sample preparation and before $\mathrm{MeOH}$ was added, the plates were centrifuged for $30-60 \mathrm{~min}\left(3000 \times g, 4^{\circ} \mathrm{C}\right)$. The clear filtrate could be directly injected into the LC-MS/MS 
system without further processing and without the need to add methanol. Where an increase in sensitivity was needed, the filtrate could be evaporated to dryness with nitrogen and resolubilized with an appropriate amount of acidified mobile phase.

\section{Animals}

\section{Mice \& sample collection}

The mouse samples used in this method development study were remaining samples from mice studied in other, nonrelated experiments. No mouse was experimented upon specifically for the purpose of the present study. Samples obtained from C57BL/6J mice were used to determine feasibility of plasma and brain tissue measurement of TRYCATs. Blood was usually collected via puncture of the facial vein (submandibular blood collection) or as trunk blood after decapitation. Plasma was generated after centrifugation for $10 \mathrm{~min}$ at $2000 \times g$ at $4^{\circ} \mathrm{C}$. Whole brains were snap frozen in liquid nitrogen.

\section{Nonhuman primates}

All experimental procedures were carried out under the regulations set by the European Communities Council Directive 24 November 1986 (86/609/ EEC), approved by the Institute of Laboratory Animal Science Ethical Committee, and completed in an AAALAC-accredited facility at Motac Neuroscience. Two captive bred male cynomolgus macaques (Macaca fascicularis; Xierin, Beijing) were housed individually in cages with food and water available ad libitum. The conditions of the housing environment were controlled (humidity, temperature, 12-h light/dark cycle with lights on from 8:00 am to 8:00 pm). Animal care was provided by highly skilled veterinarians and technicians.

\section{L-KYN challenge in nonhuman primates}

Nonhuman primates were administered with either L-KYN (30 mg/kg, iv.) or saline vehicle (VEH, iv.) 3 days apart. Vehicle was administered first. Blood was collected at 0 and $8,15,30,60,90,120,180$ and $240 \mathrm{~min}$ after administration of L-KYN or vehicle. CSF was collected by lumbar puncture at $120 \mathrm{~min}$ after administration. One of the CSF samples from $\mathrm{VEH}$-treated subjects was blood contaminated and, therefore, excluded from data analysis. Sampling was performed as described previously [46].

\section{Brain tissue microdissection for region-specific analysis}

Frozen mouse brains were placed in a stainless steel mouse brain matrix and cut coronally at $1-\mathrm{mm}$ intervals using single-edged blades [47]. The fol- lowing regions were microdissected using a brain punch $(\varnothing=1 \mathrm{~mm})$ and a mouse brain atlas [48] from the corresponding sections: infralimbic cortex (IL, Bregma 2.0-1.0 mm, 1 biopsy/hemisphere), anterior cingulate cortex (ACC, Bregma 2.0-1.0 mm, 1 biopsy/hemisphere), nucleus accumbens (NAcc, Bregma 1.0-0.0 mm, 2 biopsies/hemisphere), dorsal striatum (CPu, Bregma 0.0 to $-1.0,2$ biopsies/hemisphere), amygdala (AMY, Bregma -1.0 to $-2.0 \mathrm{~mm}$, 1 biopsy/hemisphere), dorsal hippocampus (dHIP, Bregma -1.0 to -2.0, 1 biopsy/hemisphere), ventral hippocampus (vHIPP, -3.0 to $-4.0 \mathrm{~mm}, 3$ biopsies/hemisphere), ventral tegmental area (VTA, Bregma -3.0 to $-4.0,1$ biopsy/hemisphere), dorsal raphe nucleus (DRN, -4.0 to $-5.0 \mathrm{~mm}, 1$ medial biopsy), median raphe nucleus (MRN, Bregma -4.0 to $-5.0,1$ medial biopsy). Microdissection was conducted at $-20^{\circ} \mathrm{C}$ and brain biopsies were weighed and stored at $-80^{\circ} \mathrm{C}$ until analysis.

\section{Results \& discussion}

Evaluation \& optimization of multiple reaction monitoring transitions \& MS-specific parameters, selectivity

Each analyte and IS was first infused into the mass spectrometer and tuned for its molecular transitions. This was done using acidic ( $0.1 \% \mathrm{FA})$, neutral and basic $(0.1 \%$ ammonium hydroxide solution) modifiers and various percentages of $\mathrm{MeOH}$ and $\mathrm{ACN}$ in order to check for molecule-specific ionization in positive or negative ESI mode, and to gain first hints on sensitivity. At first, several multiple reaction monitoring (MRM) transitions (2-3) per molecule were used for method development (quantifiers and qualifiers). All transitions were checked for cross-talk and also for their specificity in biological samples. In addition, the Human Metabolome Database [49] was searched for similar transitions which could potentially interfere and impact on analytical specificity. Finally, for each molecule one specific MRM transition was selected (Table 1), no interference could be observed for the selected transition. Manual tuning of ion source and mass spectrometric parameters was performed to optimize signal as well as $\mathrm{S} / \mathrm{N}$; collision gas was set to 9 (Table 1). Positive ESI mode turned out to be superior for all molecules - even for those with carboxylic functional groups without primary amine function (QUIN, PICO, KYNA and XANA).

Since ion source parameters are dependent on flow rate and mobile phase composition, these parameters were optimized via flow injection analysis after HPLC method development was done and final mobile phase conditions, gradients, etc., were established (see below for the section 'Optimization of ion source parameters'). 


\section{HPLC method development}

Various stationary phases were tested for their retention of the TRP metabolites - considering the physicochemical properties and hydrophilic as well as lipophilic characteristics of the TRYCATs. Common to all molecules is a rather hydrophobic but small $\pi$-system of phenyl or indole structure. Despite this, various functional groups - hydroxy, carboxy and/or amine - give rise to the hydrophilicity of the molecules and could serve as ionic functions. Therefore, the mobile phase $\mathrm{pH}$ is also very important for retention. Consequently, stationary phases were tested under acidic $(\mathrm{pH} 2-3)$, rather neutral $(\mathrm{pH} \mathrm{5-7)}$ and basic $(\mathrm{pH}$ 7-9) conditions, using FA/ammonium formate or ammonium hydroxide/ammonium formate buffer systems in water (mobile phase A) and methanol (mobile phase B). Among the stationary phases tested were RP C18, RP Phenyl and hydrophilic interaction LC (HILIC) materials. Columns based on HILIC (SeQuant ZIC-HILIC and Waters Atlantis HILIC Silica) were not reliable in terms of separation and peak shape. Restek Ultra Quat and Restek Allure PFP Propyl columns were also tested and did not result in satisfactory separation. RP C18 and Phenyl columns were better in performance regarding peak separation: A Thermo Hypersil Gold column $(100 \times 2.1 \mathrm{~mm} ; 3 \mu \mathrm{m})$ provided good results for all analytes, except 3-HK and QUIN which were not retained.
Using a YMC-Triart Phenyl column $(150 \times 3 \mathrm{~mm}$; $3 \mu \mathrm{m})$ it was possible to retain $3-\mathrm{HK}$ as well. However, QUIN was also not retained sufficiently on this column and analytical run-time was quite long due to column dimensions. In order to increase throughput another column was tested. The Thermo Accucore Phenyl Hexyl phase $(50 \times 2.1 \mathrm{~mm})$ resulted in good peak shape for all analytes - even for QUIN - and satisfactory runtime of 4 min per sample. At that time, mobile phase conditions were chosen as follows: mobile phase A $0.1 \%$ FA in water; mobile phase B $0.1 \% \mathrm{FA}$ in $\mathrm{MeOH}$. By replacement of $\mathrm{MeOH}$ with $\mathrm{ACN}$, peaks were shaped even narrower. However, when samples were analyzed, this short column revealed considerable matrix effects making it inappropriate for use with plasma and tissue samples without excessive sample cleanup.

Finally a GRACE VisionHT C18 column $(100 \times$ $2.1 \mathrm{~mm} ; 3 \mu \mathrm{m}$ ) was introduced, and with addition of $0.01 \%$ TFA as mobile phase modifier, optimization of the gradient profile (Figure 2) and a flow rate of $400 \mu \mathrm{l} / \mathrm{min}$, all analytes were retained and resulted in narrow peaks (Figure 2). Column oven temperature was set at $15^{\circ} \mathrm{C}$ which resulted in an even better peak shape. The gradient was also optimized to allow for further addition of metabolites as well as tool compounds of interest. This enables investigations on PK/PD relationships in a single study within a single measurement run

Table 1. Mass transitions, declustering potential and collision energy.

\begin{tabular}{|lllll|}
\hline Analyte & Q1 mass $(\mathrm{m} / \mathbf{z})$ & Q3 mass $(\mathrm{m} / \mathbf{z})$ & DP $(\mathrm{V})$ & CE (V) \\
\hline Tryptophan & 205.1 & 118.0 & 39.0 & 28.0 \\
\hline Kynurenine & 209.1 & 94.1 & 41.0 & 19.6 \\
\hline 3-OH-kynurenine & 225.1 & 110.0 & 41.4 & 22.9 \\
\hline 3-OH-anthranilic acid & 154.0 & 136.0 & 40.0 & 17.0 \\
\hline Quinolinic acid & 168.0 & 124.0 & 33.0 & 19.7 \\
\hline Picolinic acid & 124.0 & 78.0 & 36.0 & 29.0 \\
\hline Kynurenic acid & 190.1 & 162.0 & 65.0 & 24.0 \\
\hline Xanthurenic acid & 206.0 & 178.0 & 66.0 & 25.5 \\
\hline Serotonin & 177.1 & 160.0 & 37.0 & 15.0 \\
\hline Dopamine & 154.1 & 137.0 & 42.0 & 15.0 \\
\hline Neopterin & 254.1 & 206.1 & 85.5 & 26.2 \\
\hline Melatonin & 233.1 & 174.0 & 50.0 & 21.5 \\
\hline IDO inhibitor & 438.1 & 359.0 & 75.0 & 22.0 \\
\hline d5-Tryptophan & 210.1 & 122.1 & 38.0 & 39.8 \\
\hline d4-Kynurenine & 213.1 & 140.1 & 39.0 & 21.0 \\
\hline d3-Quinolinic acid & 171.0 & 127.0 & 37.0 & 20.0 \\
\hline d5-Kynurenic acid & 195.1 & 167.1 & 65.0 & 24.0 \\
\hline d4-Serotonin & 181.1 & 164.0 & 36.0 & 18.0 \\
\hline d4-Dopamine & 158.1 & 141.1 & 42.0 & 15.5 \\
\hline
\end{tabular}


and to expand the method to related metabolites and research compounds. The retention times of analytes are shown in Table 2 and scheduled MRM was carried out to monitor transitions only in a discrete time window in order to increase dwell time for each transition and to have at least $10-15$ data points per peak. A guard column $(5 \times 2.0 \mathrm{~mm})$ of the same column material was introduced to protect the analytical column from contamination. A column switching valve placed after the analytical column was programmed to switch flow onto MS only when analytes of interest elute from the column $(0.8-2.95 \mathrm{~min})$ to prevent excessive contamination of ion source and ion optics. Washing procedures of the Autosampler before and after injection of samples were programmed in order to avoid carry-over of analytes.

The final gradient was chosen as follows (please also refer to Supplementary Table 1): $0.0 \mathrm{~min}(3 \% \mathrm{~B})$, $0.3 \min (3 \% \mathrm{~B}), 0.8 \min (30 \% \mathrm{~B}), 1.8 \min (60 \% \mathrm{~B})$, $2.5 \min (60 \% \mathrm{~B}), 3.0 \min (95 \% \mathrm{~B}), 4.4 \min (95 \% \mathrm{~B})$, $4.5 \min (3 \% \mathrm{~B})$ and $5.5 \mathrm{~min}(3 \% \mathrm{~B})$.

Routinely applied calibration ranges and correlation coefficients are presented in Supplementary Table 3. The retention times of analytes, their retention factors and the efficiency of separation are presented in Supplementary Table 4.

\section{Optimization of ion source parameters}

With the final mobile phase composition and flow rate evaluated before, flow injection analysis and continuous infusion in the mobile phase flow was carried out. Optimization of ion source parameters should lead to high signal intensity when analyte is present, and low noise in the absence of analytes with the aim of achieving a high $\mathrm{S} / \mathrm{N}$. Therefore, a mixture of $70 \%$ mobile phase A and $30 \%$ of mobile phase B was used and the analytes were directly injected in the mobile phase flow without column separation. Step-by-step ion source parameters were optimized and resulted in curtain gas of 35 , ionization gas of 40 , heater gas of 65 , ion spray voltage of $3000 \mathrm{~V}$ and a temperature of $650^{\circ} \mathrm{C}$.

\section{Evaluation of matrix effects}

By using a t-fitting directly after the column, a continuous flow of analyte mixture was added to the eluate during an analytical run and after injection of a matrix sample. This allowed us to visually assess and determine matrix effects in the presence of all analytes throughout the whole chromatogram, when matrix like processed plasma or brain tissue was injected. No severe matrix effects were observed in the window of elution of compounds. Moderate but acceptable matrix effects were observed for early eluting compounds like QUIN, $\mathrm{NEO}$ and DA, especially in brain tissue samples. These

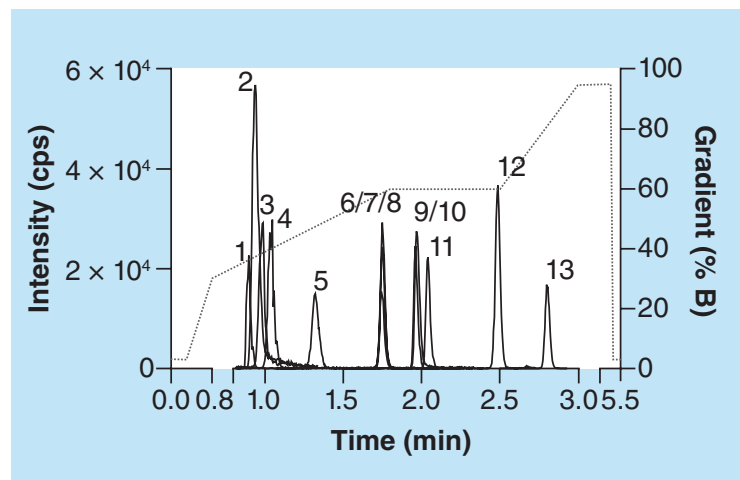

Figure 2. Representative chromatogram of a standard sample (1 neopterin [1000 nM], 2 quinolinic acid [250 $\mathrm{nM}]+$ d5-quinolinic acid, 3 picolinic acid [1000 nM], 4 dopamine [500 nM] + d4-dopamine, 5 3-hydroxykynurenine [1000 nM], 6 kynurenine [1000 nM] + d4-kynurenine, 7 serotonin [250 nM] + d4-serotonin, 8 3-hydroxyanthranilic acid [1000 nM], 9 tryptophan [1000 nM] + d5-tryptophan, 10 xanthurenic acid [ $250 \mathrm{nM}], 11$ kynurenic acid [250 nM] + d5-kynurenic acid, 12 melatonin [25 nM], 13 IDO1 inhibitor [500 nM], dotted line represents the theoretical gradient profile).

effects did not impact on accuracy or precision and were compensated by the use of deuterated IS (Table 2) which was also confirmed by spiking experiments. Further assessment of matrix effects has been performed in relation to FDA and EMA guidelines on bioanalytical method validation $[44,45]$. As endogenous concentrations of analytes are present in matrices evaluated (plasma, CSF and brain), matrix effects were determined with IS only and the matrix factor of IS calculated. Results of the IS analyte area in matrix versus IS analyte area in blank samples are presented in Supplementary Table 2. Furthermore, the determination of accuracy and precision in matrix (presented below) as well as the continuous use of matrix-based QCs, confirms for all analytes, except for MEL and partly 3-HAA, that correction by the selected IS does justify and support analytical performance.

\section{Accuracy \& precision, \& sensitivity}

Accuracy and precision were determined based on the FDA guideline on validation of bioanalytical methods [44], in pooled mouse plasma samples spiked with several concentrations of analyte mixture (standard addition method). Each validation sample concentration was measured in a total of three to five replicates on at least three independent days in order to calculate within- and between-run accuracy and precision (Table 2). Except for 3-HAA and MEL, we found acceptable accuracy. Precision was acceptable for all analytes, except for MEL. For 3-HAA, precision was borderline acceptable. As accuracy of 3-HAA was lower as for the other analytes (59-74\%) but rather stable 
Table 2. Retention times, assigned internal standard, LLOQ and accuracy and precision.

\begin{tabular}{|c|c|c|c|c|c|c|c|}
\hline \multirow[t]{2}{*}{ Analyte } & \multirow[t]{2}{*}{$t_{R}(\min )$} & \multirow[t]{2}{*}{ IS } & \multicolumn{2}{|c|}{ Accuracy (\%) } & \multicolumn{2}{|c|}{ Precision (\%) } & \multirow[t]{2}{*}{ LLOQ (nM) } \\
\hline & & & Within-run & Between-run & Within-run & Between-run & \\
\hline Tryptophan & 1.98 & d5-TRP & $100-111$ & $97-108$ & $1.2-5.9$ & $2.5-5.4$ & 2.5 \\
\hline 3-OH-kynurenine & 1.31 & d4-KYN & $81-100$ & $90-94$ & $2.4-6.8$ & $3.9-10.3$ & 0.75 \\
\hline 3-OH-anthranilic acid & 1.79 & d4-KYN & $42-67$ & $59-74$ & $13-23$ & $14-20$ & 1.0 \\
\hline Picolinic acid & 1.02 & d3-QUIN & $97-105$ & $101-116$ & $3.6-6.6$ & $4.7-14.3$ & 10 \\
\hline Kynurenic acid & 2.04 & d5-KYNA & $95-100$ & $99-109$ & $2.4-4.5$ & $3.4-7.3$ & 0.25 \\
\hline Xanthurenic acid & 1.98 & d5-TRP & $89-100$ & $95-111$ & $3.8-9.6$ & $6.2-11.5$ & 0.25 \\
\hline Serotonin & 1.78 & d4-5-HT & 99-102 & $100-101$ & $1.0-6.9$ & $2.5-3.3$ & 0.25 \\
\hline IDO-inhibitor & 2.75 & & & \multicolumn{4}{|c|}{ Represents an example for individualization of the method } \\
\hline
\end{tabular}

between runs, we recommend the use of 'relative to Control' instead of absolute concentrations for this analyte. The LLOQ (Table 2) was determined in matrixfree calibration standards which underwent the whole sample preparation procedure.

Since deuterated IS were not available for all of the evaluated analytes in our laboratory, the assigned IS for 3-HK, PICO, XANA, NEO and MEL were chosen based on structural similarity to the IS chemical structure and closeness of retention time as well as best results for accuracy and precision. This approach failed for MEL. Introduction of a deuterated MEL IS is recommended for quantification of this analyte. The introduction of a deuterated standard for 3-HAA, may improve performance for this analyte as well.

The determination of accuracy and precision in matrix as well as the continuous use of matrix-based QCs (plasma, brain, CSF), confirms for all analytes, except for MEL and partly 3-HAA, that the evaluated analytes can be measured accurately and precisely, and correction by the selected IS does support analytical performance and displays fit-for-purpose qualification of the evaluated method.

Both methods of sample preparation have been applied and were found to deliver similar quantitative results. Calibration standards and prepared QCs passed acceptance criteria as well. For application in our studies, the sample preparation with ultrafiltration has been applied. It is less labor intensive and allows for higher throughput. The method has been applied already in two studies [50,51]. Further manuscripts are in preparation representing results from human species and further mouse studies, including measurements in CSF.
Determination of TRYCATs, DA \& NEO in plasma \& CSF after challenge with L-KYN in nonhuman primates

A time course of TRYCATs is shown in Figure 3. After KYN treatment animals exhibited a rapid increase in plasma KYN (Figure 3B) and 3-HK (Figure 3C) with its maximum $\left(\mathrm{t}_{\max }\right)$ after $8-15 \mathrm{~min}$. After $240 \mathrm{~min}$ 3-HK-levels were back to baseline, whereas KYN was still three- to fivefold above control (CON) levels. KYN is metabolized to QUIN via $3-\mathrm{HK}$ and 3-HAA. The rapid increase in KYN and 3-HK was followed by a sustained increase in QUIN (Figure 3D); QUIN reached a maximum after around $120 \mathrm{~min}$ and stayed elevated even beyond the $240 \mathrm{~min}$ investigated. KYNA (Figure 3F) also increased rapidly and markedly ( $\mathrm{C}_{\max } \sim 75$-fold compared with baseline) but only in one of the two subjects, exhibiting the same $t_{\max }$ as compared with KYN and 3-HK. The second subject exhibited a less pronounced $\mathrm{C}_{\text {max }}$ almost tenfold above vehicle control. XANA increased markedly in one animal and only moderately in the second KYN-treated animal (Figure 3G). The lower increase in plasma KYNA and XANA of subject 2 might be explained by, for example, a functional difference in peripheral KAT-enzymes due to a mutation [52]. No effect was observed on plasma neopterin levels (Figure $3 \mathrm{H}$ ). Plasma TRP levels rose gradually in one of the two vehicle-treated animals (Figure 3A). The mean baseline plasma levels before treatment are displayed in Table 3.

CSF was collected at $120 \mathrm{~min}$ after KYN administration (Table 3 ), representing the approximated $t_{\max }$ of plasma QUIN. In CSF of treated animals, KYN, 3-HK, QUIN and KYNA were higher compared with 
vehicle control. Surprisingly, compared with plasma, CSF KYNA was higher in both animals and to a comparable extent, which did not reflect the diminished increase in plasma KYNA in one of the two subjects studied. In line with literature, this finding suggests that the peripheral and central production of KYNA is not uniform, meaning that peripheral KYNA levels do not necessarily predict CSF levels and could lead to misinterpretation of data when only plasma is measured in (pre-)clinical studies [53-56]. Plasma TRP and plasma and CSF NEO were largely unaffected by the KYN application. CSF TRP was lower after KYN treatment, probably due to concurrent transport with KYN into the brain via the LAT-1 [53], which could lead to a slightly reduced availability of TRP in the brain. XANA, which is also produced by KATs, was higher only in one of the two subjects in plasma and CSF.

Baseline plasma and CSF levels at least for KYN, QUIN and KYNA have been reported in the literature and seem to be variable from study to study or species [57,58]. Levels for serum and CSF KYN and KYNA are comparable to levels determined in our study [57].

\section{Determination of TRYCATs, DA \& NEO in} plasma \& corticolimbic brain regions in mice

Another application of the previously established method is shown by analysis of plasma samples and brain samples (region-specific analysis of IL, ACC, NAcc, CPu, BLA, dHIP, vHIP, VTA, DRN, MRN) from mice (Table 4 \& Figure 4). In plasma, all metabolites were well above the LLOQ, except for MEL and NEO (Table 4). NEO was not measurable in mice but was so in monkeys. A possible explanation for this finding is that NEO was found to be much more rapidly metabolized in mice compared with monkey and human, and is not produced from peripheral blood mononuclear cells in mice subsequent to immune stimulation [31,59]. In low amounts of brain samples (depending on the brain region, amount of tissue between 1 and $3 \mathrm{mg}$ ) it was possible to measure TRP, KYN, 3-HK, 5-HT and DA. Different concentrations were determined depending on the brain region (Figure 4A-F). The calculation of the KYN/TRP ratio might help to reduce intersubject variability in the measurement of the single metabolites of KYN and TRP (Figure 4A-C). KynA and QUIN were around the LLOQ and were barely quantifiable, 3-HAA was below LLOQ. Our data confirm previously published data $[33,34]$.

\section{Conclusion}

Herein we report a rapid and sensitive LC-MS/MS method for the determination of 11 important biomarkers, namely TRP and seven of its KYN pathway metabolites (KYN, 3-OH-KYN, 3-OH-anthranilic acid, QUIN, PICO, KYNA, XANA), the inflammation marker NEO and the related neurotransmitters serotonin and DA, in a single run and within $5.5 \mathrm{~min}$. Despite the hydrophilic nature of metabolites such as QUIN and the rather hydrophobic nature of, for example, TRP in addition to differences in functional groups, we could establish reversed phase LC to retain all of the mentioned analytes without the need for additional derivatization steps. The established gradient also offers the possibility to integrate more lipophilic analytes like pharmaceutical compounds to adapt it to individual needs and expand the panel of analytes assessed. Furthermore, the method shows applicability not only for plasma or serum but is also sensitive enough to reliably measure most of the metabolites in complex matrices such as CSF and to some extent brain tissue; two compartments with much lower endogenous levels compared with plasma. Our method overcomes the challenges of marked differences in endogenous baseline levels among analytes and has been applied over a wide concentration range (6 orders of magnitude). Sample preparation and analysis were optimized for sufficient throughput: the short analytical run-time of $5.5 \mathrm{~min}$ and the simple sample preparation procedure are the basis for cost efficient and time efficient routine applicability. The gradient was also optimized to allow for further addition of metabolites as well as tool compounds of interest. Altogether, this enables investigations on PK/PD relationship and biomarkers in a single study within a single measurement run per sample or subject and to expand the method to related metabolites and research compounds.

Compared with previous methods, our method shows some advantages, namely: low sample volumes of only few microliters of CSF and plasma can be reliably measured with adequate sensitivity; adequate throughput for cost-efficient and time-efficient routine sample analysis is ensured by a short run-time of $5.5 \mathrm{~min}$ and a simple sample preparation procedure; next to KYN metabolites, the related neurotransmitters DA and serotonin as well as NEO as marker for IFN- $\gamma$ induction can be measured; the method can be expanded to further molecules and research compounds easily within the established gradient. Applications and adequate sensitivity of this method have been displayed by the measurement of monkey CSF and plasma. Furthermore, manuscripts describing the application to CSF from human subjects and mice are under preparation. The low sample amount of only $10 \mu \mathrm{l}$ CSF becomes most important, when CSF from mice should be measured. Usually less than $20 \mu \mathrm{l} \mathrm{CSF}$ can be collected from mice. The simple sample preparation and simultaneous measurement of metabolites - without the need for derivatization - allows for reliable measurements in plasma and 


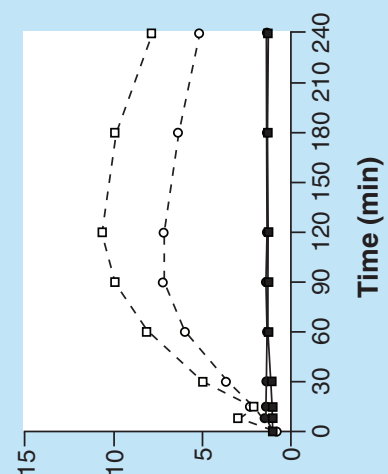

(D) (I//ourl) p!̣อ ग!u!|ou!no

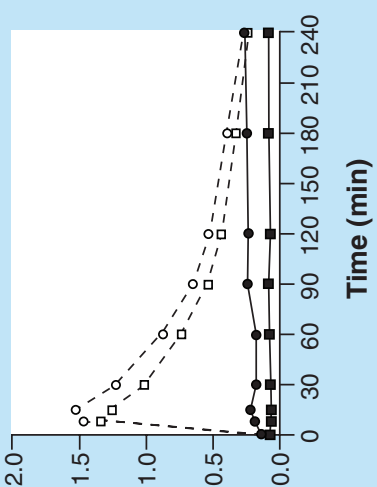

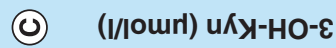

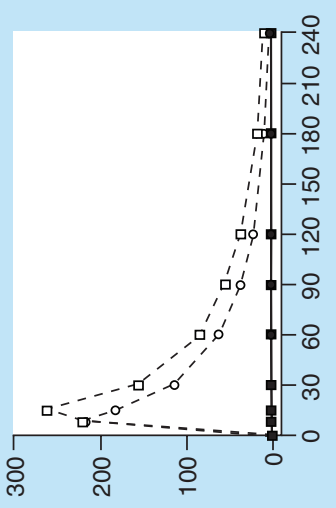

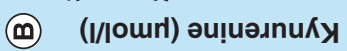

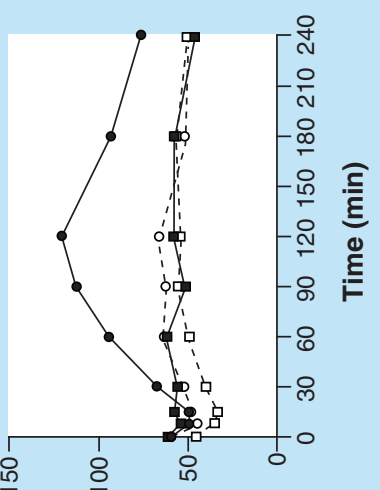

(๔) (I//ourl) ueydold $K_{\perp}$
(I)

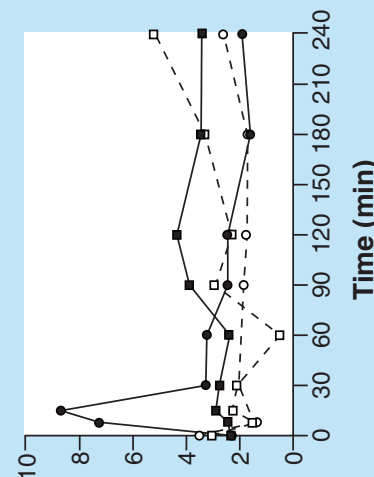

(I//ouu) u!ıәฺdoәN

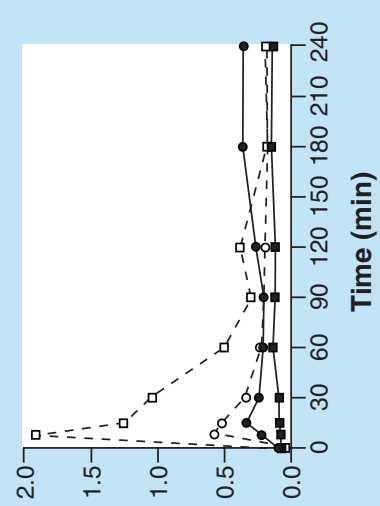

(C) (I/lourl) p!эe ग!นәлnчłuex

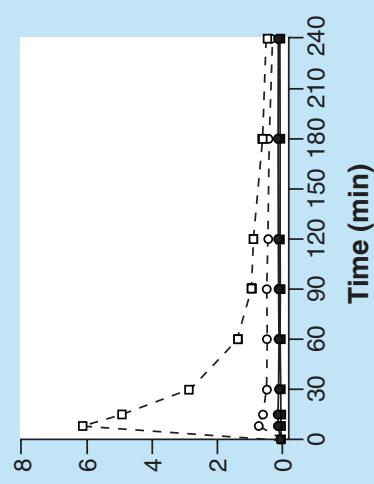

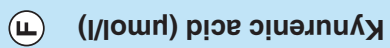

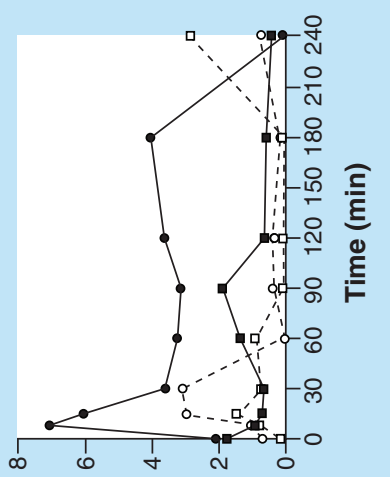

(ய) (I/lourl) u!̣uopodəs

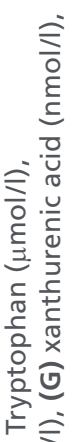

$\varangle \stackrel{\circ}{\varepsilon}$

을 등

일

.

ริํำ

혼

范药

들

월

ఫे

ข 눙 흐

를

จำ

ํํ든

ह

ํํ

을

禀.

ธิ

은

ญ

초

ऐั

월

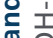

운

을

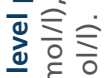

过

똔 लं ํㅣㄱ 홍 
Table 3. Tryptophan catabolites, dopamine and neopterin baseline plasma levels and cerebrospinal fluid levels in monkey cerebrospinal fluid $2 \mathrm{~h}$ post kynurenine challenge $(30 \mathrm{mg} / \mathrm{kg} \mathrm{iv}$.$) .$

\begin{tabular}{|c|c|c|c|c|c|}
\hline \multirow[t]{2}{*}{ Analyte } & \multicolumn{4}{|c|}{ CSF } & \multirow[t]{2}{*}{ Plasma (mean) } \\
\hline & CON2 & KYN1 & KYN2 & $\mathrm{CON}^{+}$ & \\
\hline Tryptophan (nmol/l) & 2340 & 1780 & 1980 & $5320^{+}$ & 60,450 \\
\hline Kynurenine (nmol/l) & 17.3 & 856 & 728 & $130^{+}$ & 1435 \\
\hline 3-OH-kynurenine (nmol/l) & 1.8 & 17.3 & 11.8 & $8.1^{\dagger}$ & 106 \\
\hline Quinolinic acid (nmol/l) & 52.0 & 262 & 151 & $133^{+}$ & 1010 \\
\hline Kynurenic acid (nmol/l) & 1.7 & 31.4 & 43.6 & $5.0^{+}$ & 52.3 \\
\hline Xanthurenic acid (nmol/l) & 0.8 & 1.0 & 3.7 & $8.0^{+}$ & 89.3 \\
\hline Serotonin (nmol/l) & $<$ LLOQ & $<$ LLOQ & 2.0 & $282^{+}$ & 1935 \\
\hline Neopterin (nmol/l) & 1.9 & 2.6 & 1.2 & $1.4^{+}$ & 2.3 \\
\hline Dopamine (nmol/l) & $<$ LLOQ & $<$ LLOQ & $<$ LLOQ & $<$ LLOQ & $<$ LLOQ \\
\hline
\end{tabular}

almost all metabolites in CSF and to some extent brain tissue with reasonable throughput which also has been displayed in two publications already [50,51].

Limitations of the method are: MEL could not be reliably assessed in the current setting of this method and accuracy and precision was out of acceptable range. Addition of an appropriate IS like deuterated MEL might solve this issue. Furthermore, not all metabolites could be measured sensitive enough in all the species and in all matrices. For example, it was not possible to measure QUIN and KYNA in mouse brain tissue, but it was possible to measure these metabolites in CSF from monkeys. NEO could not be detected in plasma, CSF and brain tissue from mice, but was measureable in monkey plasma. This limitation, one could overcome by transfer of the method to an even more sensitive MS system.

In a small study with nonhuman primates we could additionally show that changes in KYN and 3-HK plasma levels impact directly on the CSF levels of these metabolites. In contrast this was not the case for KYNA, where a pronounced increase in plasma KYNA was only seen in one of the two animals but CSF levels were higher in both animals compared with control and to a comparable extent. Hence, plasma KYNA levels do not necessarily predict brain KYNA levels which should be taken into account when TRYCATs are measured in (pre-)clinical studies, especially if plasma is the only available sample source. Furthermore, we established baseline KYN metabolite concentrations in plasma and CSF of nonhuman primates (Macaca fascicularis) and in plasma and ten brain regions in mice.

\section{Future perspective}

Single molecule analyses are important techniques in preclinical and clinical sample analysis; they are eas- ily applied and deliver robust results once established. However, especially the simultaneous measurement of drug compounds together with several biomarkers becomes increasingly important in research and drug development. Ideally, a tool compound or a drug development candidate shall be measured simultaneously together with biomarkers for the disease population, for target engagement, of efficacy and/or of safety from a single sample and in one analytical method. This approach would not only save time and money, it would increase confidence in the mechanism of action, the therapeutic concept and in the end the development candidate. In every individual, assessment of disease status, compound exposure, target engagement, efficacy and safety would be possible. Restrictions in sample volumes are another issue; one example for this is mouse CSF where often only a few

\begin{tabular}{|c|c|}
\hline Analyte & $C_{\text {Plasma }}(n=8)$ \\
\hline Tryptophan ( $\mu \mathrm{mol} / \mathrm{l})$ & $90 \pm 13$ \\
\hline Kynurenine (nmol/l) & $606 \pm 58$ \\
\hline 3-OH-kynurenine $(\mathrm{nmol} / \mathrm{l})$ & $75 \pm 16$ \\
\hline 3-OH-anthranilic acid ( $\mathrm{nmol} / \mathrm{l})$ & $9.7 \pm 2.4$ \\
\hline Quinolinic acid (nmol/l) & $196 \pm 60$ \\
\hline Picolinic acid (nmol/l) & $334 \pm 46$ \\
\hline Kynurenic acid (nmol/l) & $47 \pm 18$ \\
\hline Xanthurenic acid (nmol/l) & $56 \pm 14$ \\
\hline Serotonin $(\mu \mathrm{mol} / \mathrm{l})$ & $8.9 \pm 5.5$ \\
\hline Neopterin & $<$ LLOQ \\
\hline Dopamine (nmol/l) & $23 \pm 6$ \\
\hline
\end{tabular}


(A)

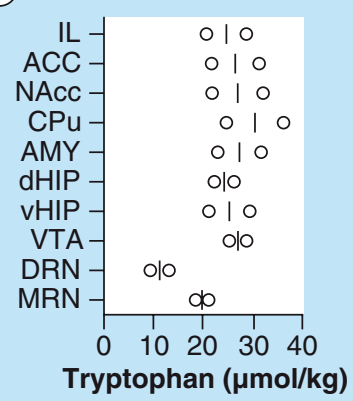

(D)

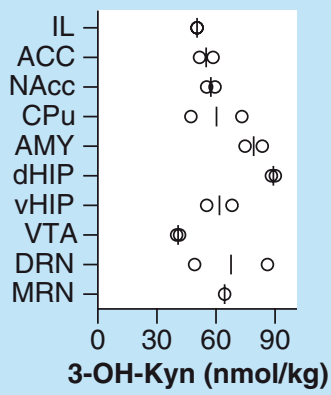

(B)

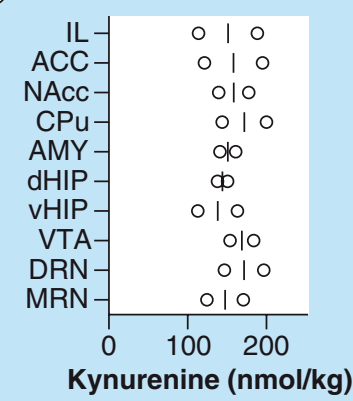

(E)

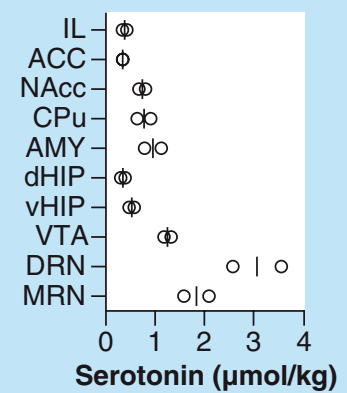

(c)

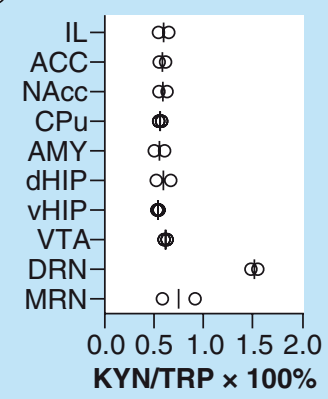

(F)

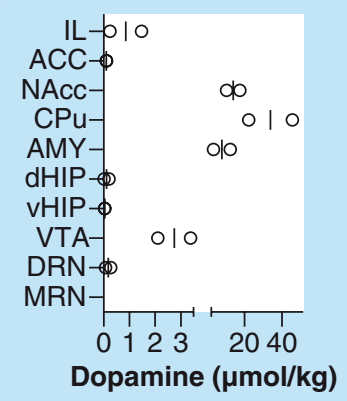

Figure 4. Basal TRYCAT levels as well as $5-\mathrm{HT}$ and DA in ten mouse brain regions. (A) tryptophan $[\mu \mathrm{mol} / \mathrm{kg}]$, (B) kynurenine [nmol/kg], (C) KYN/TRP ratio [\%] (D) 3-OH-kynurenine [nmol/kg], (E) serotonin $[\mu \mathrm{mol} / \mathrm{kg}]$, (F) dopamine $[\mu \mathrm{mol} / \mathrm{kg}]$. ACC: Anterior cingulate cortex; AMY: Amygdala; CPu: Caudate putamen; DA: Dopamine; dHIP: Dorsal hippocampus; DRN: Dorsal raphe nucleus; IL: Infralimbic cortex; KYN: Kynurenine; MRN: Median raphe nucleus; NAcc: Nucleus accumbens; TRP: Tryptophan; TRYCAT: Tryptophan catabolites; vHIP: Ventral hippocampus; VTA: Ventral tegmental area.

microliters can be collected. Methods which are able to answer multiple questions by determining a number of analytes yield more results out of a limited sample volume and in the end also reduce the number of animal subjects needed per study. Furthermore, PK/PD relationships could be established as early as possible. Also, once a reliable method is established, time and cost-effectiveness will further be optimized, as multiple sample preparations and multiple analytical runs will not be necessary.

In the future we will see more targeted metabolomic techniques combined with compound measurement and this will increase our understanding of how drug compounds affect a physiological system to an important extent.

\section{Supplementary data}

To view the supplementary data that accompany this paper please visit the journal website at: www.future-science.com/ doi/full/10.4155/bio-2016-0111

\section{Acknowledgements}

The authors are very grateful to Christoph Reuss, Chris Cantow, Steffen Schrade and Dr Qin Li for expert technical as- sistance and to Christopher Pryce for careful proofreading and language correction.

\section{Financial \& competing interests disclosure}

This work and open access publication of this article was funded by Boehringer Ingelheim Pharma GmbH \& Co. KG. A Ceci, AH Luippold, B Hengerer and R Fuertig are employees of Boehringer Ingelheim Pharma GmbH \& Co. KG. SM Camus is an employee of Motac Neuroscience Ltd. E Bezard is a shareholder of Motac Neuroscience Ltd. The authors have no other relevant affiliations or financial involvement with any organization or entity with a financial interest in or financial conflict with the subject matter or materials discussed in the manuscript apart from those disclosed.

No writing assistance was utilized in the production of this manuscript.

\section{Ethical conduct of research}

The authors state that they have obtained appropriate institutional review board approval or have followed the principles outlined in the Declaration of Helsinki for all human or animal experimental investigations. In addition, for investigations involving human subjects, informed consent has been obtained from the participants involved. 


\section{Open access}

This work is licensed under the Attribution-NonCommercial-NoDerivatives 4.0 Unported License. To view a copy of this license, visit http://creativecommons.org/licenses/bync-nd/4.0/

\section{Executive summary}

\section{Background}

- To investigate the kynurenine pathway, neurotransmitters and compound levels simultaneously, an LC-MS/MS method was developed to quantify 11 molecules of interest.

\section{Experimental}

- A 5.5-min LC-MS/MS method was established in multiple reaction monitoring mode and without derivatization steps.

- Low sample volumes are needed, simple sample preparation by protein precipitation, introduction of ultrafiltration possible, evaluated matrices are plasma, CSF and brain tissue.

\section{Results \& discussion}

- A sensitive and reliable method could be established which allows a reasonable throughput and cost- and time-efficient routine analysis.

- Three applications of this method were successfully presented - measurement of: monkey plasma and CSF after kynurenine challenge; baseline mouse plasma; and mouse brain tissue.

\section{References}

1 Metz R, Duhadaway JB, Kamasani U, Laury-Kleintop L, Muller AJ, Prendergast GC. Novel tryptophan catabolic enzyme IDO2 is the preferred biochemical target of the antitumor indoleamine 2,3-dioxygenase inhibitory compound D-1-methyl-tryptophan. Cancer Res. 67(15), 7082-7087 (2007).

2 Ball HJ, Jusof FF, Bakmiwewa SM, Hunt NH, Yuasa HJ. Tryptophan-catabolizing enzymes - party of three. Front. Immunol. 5, 485 (2014).

3 Lob S, Konigsrainer A, Rammensee HG, Opelz G, Terness P. Inhibitors of indoleamine-2,3-dioxygenase for cancer therapy: can we see the wood for the trees? Nat. Rev. Cancer 9(6), 445-452 (2009).

4 Sedlmayr P, Blaschitz A, Stocker R. The role of placental tryptophan catabolism. Front. Immunol. 5, 230 (2014).

5 Robinson CM, Shirey KA, Carlin JM. Synergistic transcriptional activation of indoleamine dioxygenase by IFN-gamma and tumor necrosis factor-alpha. J. Interferon Cytokine Res. 23(8), 413-421 (2003).

6 Robinson CM, Hale PT, Carlin JM. The role of IFNgamma and TNF-alpha-responsive regulatory elements in the synergistic induction of indoleamine dioxygenase. J. Interferon Cytokine Res. 25(1), 20-30 (2005).

7 Durr S, Kindler V. Implication of indolamine 2,3 dioxygenase in the tolerance toward fetuses, tumors, and allografts. J. Leukoc. Biol. 93(5), 681-687 (2013).

8 Schwarcz R, Bruno JP, Muchowski PJ, Wu HQ. Kynurenines in the mammalian brain: when physiology meets pathology. Nat. Rev. Neurosci. 13(7), 465-477 (2012).

9 Chen Y, Guillemin GJ. Kynurenine pathway metabolites in humans: disease and healthy states. Int. J. Tryptophan Res. 2, 1-19 (2009).

10 Vecsei L, Szalardy L, Fulop F, Toldi J. Kynurenines in the CNS: recent advances and new questions. Nat. Rev. Drug Discov. 12(1), 64-82 (2013).
11 Opitz CA, Litzenburger UM, Sahm F et al. An endogenous tumour-promoting ligand of the human aryl hydrocarbon receptor. Nature 478(7368), 197-203 (2011).

12 Veldhoen M, Hirota K, Westendorf AM et al. The aryl hydrocarbon receptor links TH17-cell-mediated autoimmunity to environmental toxins. Nature 453(7191), 106-109 (2008).

13 Moffett JR, Namboodiri MA. Tryptophan and the immune response. Immunol. Cell Biol. 81(4), 247-265 (2003).

14 Okuda S, Nishiyama N, Saito H, Katsuki H. Hydrogen peroxide-mediated neuronal cell death induced by an endogenous neurotoxin, 3-hydroxykynurenine. Proc. Natl Acad. Sci. USA 93(22), 12553-12558 (1996).

15 Okuda S, Nishiyama N, Saito H, Katsuki H. 3-Hydroxykynurenine, an endogenous oxidative stress generator, causes neuronal cell death with apoptotic features and region selectivity. J. Neurochem. 70(1), 299-307 (1998).

16 Phillips RS. Structure and mechanism of kynureninase. Arch. Biochem. Biophys. 544 69-74 (2014).

17 Ueda T, Otsuka H, Goda K, Ishiguro I, Naito J, Kotake Y. The metabolism of [carboxyl-14C] anthranilic acid. I. The incorporation of radioactivity into NAD+ and NADP+. J. Biochem. 84(3), 687-696 (1978).

18 Bender DA, Mccreanor GM. The preferred route of kynurenine metabolism in the rat. Biochim. Biophys. Acta 717(1), 56-60 (1982).

19 Lugo-Huitron R, Ugalde Muniz P, Pineda B, PedrazaChaverri J, Rios C, Perez-De La Cruz V. Quinolinic acid: an endogenous neurotoxin with multiple targets. Oxid. Med. Cell. Longev. 2013, 104024 (2013).

20 Jhamandas KH, Boegman RJ, Beninger RJ, Miranda AF, Lipic KA. Excitotoxicity of quinolinic acid: modulation by endogenous antagonists. Neurotox. Res. 2(2-3), 139-155 (2000).

21 Parsons CG, Danysz W, Quack G et al. Novel systemically active antagonists of the glycine site of the $N$-methyl-Daspartate receptor: electrophysiological, biochemical and behavioral characterization. J. Pharmacol. Exp. Ther. 283(3), 1264-1275 (1997). 
22 Hilmas C, Pereira EF, Alkondon M, Rassoulpour A, Schwarcz R, Albuquerque EX. The brain metabolite kynurenic acid inhibits alpha7 nicotinic receptor activity and increases non-alpha7 nicotinic receptor expression: physiopathological implications. J. Neurosci. 21(19), 7463-7473 (2001).

23 Wang J, Simonavicius N, Wu X et al. Kynurenic acid as a ligand for orphan G protein-coupled receptor GPR35. J. Biol. Chem. 281(31), 22021-22028 (2006).

24 Pinto JT, Krasnikov BF, Alcutt $S$ et al. Kynurenine aminotransferase III and glutamine transaminase $\mathrm{L}$ are identical enzymes that have cysteine $S$-conjugate beta-lyase activity and can transaminate L-selenomethionine. J. Biol. Chem. 289(45), 30950-30961 (2014).

25 Nematollahi A, Sun G, Jayawickrama GS, Church WB. Kynurenine aminotransferase isozyme inhibitors: a review. Int. J. Mol. Sci. 17(6), pii: E946 (2016).

26 Han Q, Cai T, Tagle DA, Li J. Structure, expression, and function of kynurenine aminotransferases in human and rodent brains. Cell. Mol. Life Sci. 67(3), 353-368 (2010).

27 Gobaille S, Kemmel V, Brumaru D, Dugave C, Aunis D, Maitre M. Xanthurenic acid distribution, transport, accumulation and release in the rat brain. J. Neurochem. 105(3), 982-993 (2008).

28 Copeland CS, Neale SA, Salt TE. Actions of Xanthurenic acid, a putative endogenous group II metabotropic glutamate receptor agonist, on sensory transmission in the thalamus. Neuropharmacology 66, 133-142 (2013).

29 Amori L, Wu HQ, Marinozzi M, Pellicciari R, Guidetti P, Schwarcz R. Specific inhibition of kynurenate synthesis enhances extracellular dopamine levels in the rodent striatum. Neuroscience 159(1), 196-203 (2009).

30 Maes M, Scharpe S, Meltzer HY et al. Increased neopterin and interferon-gamma secretion and lower availability of L-tryptophan in major depression: further evidence for an immune response. Psychiatry Res. 54(2), 143-160 (1994).

31 Duch DS, Bowers SW, Woolf JH, Nichol CA. Biopterin cofactor biosynthesis: GTP cyclohydrolase, neopterin and biopterin in tissues and body fluids of mammalian species. Life Sci. 35(18), 1895-1901 (1984).

32 Werner ER, Werner-Felmayer G, Fuchs D et al. Tetrahydrobiopterin biosynthetic activities in human macrophages, fibroblasts, THP-1, and T 24 cells. GTPcyclohydrolase I is stimulated by interferon-gamma, and 6-pyruvoyl tetrahydropterin synthase and sepiapterin reductase are constitutively present. J. Biol. Chem. 265(6), 3189-3192 (1990).

33 Midttun O, Hustad S, Ueland PM. Quantitative profiling of biomarkers related to B-vitamin status, tryptophan metabolism and inflammation in human plasma by liquid chromatography/tandem mass spectrometry. Rapid Commun. Mass Spectrom. 23(9), 1371-1379 (2009).

34 Rider LG, Schiffenbauer AS, Zito M et al. Neopterin and quinolinic acid are surrogate measures of disease activity in the juvenile idiopathic inflammatory myopathies. Clin. Chem. 48(10), 1681-1688 (2002).

35 Badawy AA, Morgan CJ. Rapid isocratic liquid chromatographic separation and quantification of tryptophan and six kynurenine metabolites in biological samples with ultraviolet and fluorimetric detection. Int. J. Tryptophan Res. 3, 175-186 (2010).

36 Yamada K, Miyazaki T, Shibata T, Hara N, Tsuchiya M. Simultaneous measurement of tryptophan and related compounds by liquid chromatography/electrospray ionization tandem mass spectrometry. J. Chromatogr. B Analyt. Technol. Biomed. Life Sci. 867(1), 57-61 (2008).

37 Zheng X, Kang A, Dai C et al. Quantitative analysis of neurochemical panel in rat brain and plasma by liquid chromatography-tandem mass spectrometry. Anal. Chem. 84(22), 10044-10051 (2012).

38 Zhu W, Stevens AP, Dettmer K et al. Quantitative profiling of tryptophan metabolites in serum, urine, and cell culture supernatants by liquid chromatography-tandem mass spectrometry. Anal. Bioanal. Chem. 401(10), 3249-3261 (2011).

39 Meinitzer A, Tomaschitz A, Pilz S et al. Development of a liquid chromatography-mass spectrometry method for the determination of the neurotoxic quinolinic acid in human serum. Clin. Chim. Acta 436, 268-272 (2014).

40 Notarangelo FM, Wu HQ, Macherone A, Graham DR, Schwarcz R. Gas chromatography/tandem mass spectrometry detection of extracellular kynurenine and related metabolites in normal and lesioned rat brain. Anal. Biochem. 421(2), 573-581 (2012).

41 Orsatti L, Speziale R, Orsale MV et al. A single-run liquid chromatography mass spectrometry method to quantify neuroactive kynurenine pathway metabolites in rat plasma. J. Pharm. Biomed. Anal. 107, 426-431 (2015).

42 Eckstein JA, Ammerman GM, Reveles JM, Ackermann BL. Simultaneous profiling of multiple neurochemical pathways from a single cerebrospinal fluid sample using GC/MS/MS with electron capture detection. J. Mass Spectrom. 43(6), 782-790 (2008).

43 Walker AK, Budac DP, Bisulco S et al. NMDA receptor blockade by ketamine abrogates lipopolysaccharideinduced depressive-like behavior in C57BL/6J mice. Neuropsychopharmacology 38(9), 1609-1616 (2013).

44 US FDA. Guidance for industry: bioanalytical method validation. US Department of Health and Human Services, US FDA, Rockville, MD, USA. www.fda.gov

45 EMA. Guideline on bioanalytical method validation. European Medicines Agency, EMA, London, UK. www.ema.europa.eu

46 Camus SM, Blois-Heulin C, Li Q, Hausberger M, Bezard E. Behavioural profiles in captive-bred cynomolgus macaques: towards monkey models of mental disorders? PLoS ONE 8(4), e62141 (2013).

47 Azzinnari D, Sigrist H, Staehli S et al. Mouse social stress induces increased fear conditioning, helplessness and fatigue to physical challenge together with markers of altered immune and dopamine function. Neuropharmacology 85 , 328-341 (2014).

48 Paxinos G, Franklin KBJ. The Mouse Brain in Stereotaxic Coordinates. Elsevier Academic Press, USA (2008). 
Wishart DS, Jewison T, Guo AC et al. HMDB 3.0 - the human metabolome database in 2013. Nucleic Acids Res. 41, D801-D807 (2013).

Cathomas F, Fuertig R, Sigrist $\mathrm{H}$ et al. CD40-TNF activation in mice induces extended sickness behavior syndrome co-incident with but not dependent on activation of the kynurenine pathway. Brain. Behav. Immun. 50, 125-140 (2015).

51 Fuertig R, Azzinnari D, Bergamini G et al. Mouse chronic social stress increases blood and brain kynurenine pathway activity and fear behaviour: Both effects are reversed by inhibition of indoleamine 2,3-dioxygenase. Brain Behav. Immun. 54, 59-72 (2015).

52 De Souza FR, Fontes FL, Da Silva TA, Coutinho LG, Leib SL, Agnez-Lima LF. Association of kynurenine aminotransferase II gene C401T polymorphism with immune response in patients with meningitis. BMC Med. Genet. 12, 51 (2011).

53 Fukui S, Schwarcz R, Rapoport SI, Takada Y, Smith QR. Blood-brain barrier transport of kynurenines: implications for brain synthesis and metabolism. J. Neurochem. 56(6), 2007-2017 (1991).

54 Albuquerque EX, Schwarcz R. Kynurenic acid as an antagonist of alpha7 nicotinic acetylcholine receptors in the brain: facts and challenges. Biochem. Pharmacol. 85(8), 1027-1032 (2013).

55 Sekine A, Kuroki Y, Urata T, Mori N, Fukuwatari T. Inhibition of large neutral amino acid transporters suppresses kynurenic acid production via inhibition of kynurenine uptake in rodent brain. Neurochem. Res. 41(9), 2256-2266 (2016).

56 Miller JM, Macgarvey U, Beal MF. The effect of peripheral loading with kynurenine and probenecid on extracellular striatal kynurenic acid concentrations. Neurosci. Lett. 146(1), 115-118 (1992).

57 Gregoire L, Rassoulpour A, Guidetti P et al. Prolonged kynurenine 3-hydroxylase inhibition reduces development of levodopa-induced dyskinesias in parkinsonian monkeys. Behav. Brain Res. 186(2), 161-167 (2008).

58 Samadi P, Gregoire L, Rassoulpour A et al. Effect of kynurenine 3-hydroxylase inhibition on the dyskinetic and antiparkinsonian responses to levodopa in Parkinsonian monkeys. Mov. Disord. 20(7), 792-802 (2005).

59 Schoedon G, Troppmair J, Fontana A, Huber C, Curtius HC, Niederwieser A. Biosynthesis and metabolism of pterins in peripheral blood mononuclear cells and leukemia lines of man and mouse. Eur. J. Biochem. 166(2), 303-310 (1987). 